\title{
A Fundamental Study for Gamification Design: Exploring Learning Tendencies' Effects
}

\author{
Nadja Zaric ${ }^{1}$, Vlatko Lukarov ${ }^{1}$, Ulrik Schroeder ${ }^{1}$ \\ ${ }^{1}$ RWTH Aachen Univerisity, Germany \\ \{zaric, lukarov, schroeder \}@informatik.rwth-aachen.de
}

\begin{abstract}
In this paper, we present the fundamental concepts, design, and preliminary findings of a personalized gamification project in the educational context. The project aims to create a balanced, gamified learning environment in which all learners are equally engaged and interested. However, finding the balance between heterogenic learners' traits and the variety of gamification design elements is a challenging, multistep process. Therefore, this paper presents the first steps towards the design of a balanced gamified environment, in which we a) proposed the Personalized Gamification Design Model (PeGaM) to assist gamification designers in applying a learner-center approach to gamification; b) explored learners' learning tendencies as personalization criteria and applied PeGaM in the e-learning course, and c) conducted the exploratory study with 124 students to investigate behavioral differences in and between students in the control and treatment group. The study revealed a positive influence of badges, leaderboards, and experience points on learners with reflective, global, visual, and intuitive learning tendencies, and negative on students with sensing learning tendencies. Hence, this study supported the idea of introducing learning tendencies in the gamification design process and indicates the need for further research in this direction.
\end{abstract}

Keywords: Personalized Gamification, Engagement, Learning Tendendcies, Gamification Design;

\section{Introduction}

Students' engagement is composed of students' attitudes, thoughts, and behavior in learning and is defined by the time, energy thought, effort, and feelings students invest in their learning [1]. Engagement is considered to be a key indicator of a learning behavior that leads to successful learning outcomes, thus, its maintenance is vital for every educational designer [2]. In this regard, gamification - a process of incorporating game-like techniques (GLT) in non-game contexts, occurs as a promising approach to engagement boost [3]. With gamification, educational designers use collaborative, competitive, rewarding, and other game elements (GE) to increase students' interest and success. Over the past years, literature testifies it is a powerful instructional tool but also a complex process in which success depends on various factors such as demographics, behavioral, and cognitive users' traits. Hence, researchers are increasingly considering a user-centered design (UCD) to gamification. UCD is an iterative process in which designers focus on the users and their needs in each phase of the design process [4]. So far, many UC gamification designs have been reported [5], however, their effectiveness is mixed, resulting in inconsistent conclusions on how UC gamification should be designed.

In that manner, we proposed a Personalized Gamification Design Model (PeGaM), a UC model that introduces learners' learning tendencies (LTs) in the design of gamification. 
pag. 4

Learners' LTs are psychological constructs, or proxies for those constructs, that define how learners are likely to behave in a learning environment i.e. "the characteristic strengths and preferences in the ways individuals take in and process information" [6]. By introducing LTs, PeGaM aims to create a balanced gamified learning environment in which GEs are introduced in a way to address learners' learning needs. The balance is achieved through the meaningful correlation of GEs and students' needs defined by their LTs. To achieve the balance, the investigation of possible links between LTs and GEs must be conducted first. Thus, this paper presents the primary research results of PeGaM application and evaluation, in which we investigate a) whether gamification increases students' engagement, b) whether engagement is different among students concerning their LTs and c) if attitudes towards gamification vary between students with different LTs. As LTs play an important role in instructional design and can influence learners' experience [7], this study assumes that their effect is also present in gamified environments. These assumptions are explored through the exploratory experiment with 124 university students and discussed based on the qualitative and quantitative evaluations.

\section{User-Centered approach to gamification}

A UC approach to gamification is emerging, as findings have shown that desired effects are more likely if the designer can understand the relation between GE and users' characteristics. However, there is still a lack of solutions on which GEs are the most suitable for a specific gamification goal concerning specific user' traits. To assist further research on UC gamification, authors in [8] conducted a literature review in which they classified the current work in two categories - personalized and adaptive and defined five challenges (C) in regard. According to the authors, personalized UC gamification refers to studies investigating the relationship between users' traits and GEs, where two challenges ( $\mathrm{C} 1$ and C2) were identified: "the challenge of understanding the relationship between GE and their effects on different individuals" (C1) and the challenge to "examine and understand the difficulties of the development and application of different users' types inside gamified environments" (C2). On the other hand, adaptive UC gamification refers to studies in which gamification design adapts based on users' traits in real-time. As this study aims to explore potential links between GEs and LTs we position this work in the personalized gamification area [8]. In this regard, we summarize the existing studies on personalized gamification concerning learners' LTs, to reveal whether they address the afford-mentioned challenges.

To the best of our knowledge, only two studies explore the relations between learners' LTs and GEs. In [9] authors introduce LTs defined by the Honey and Mumford model together with Bartle player types and proposed a conceptual Learner-Centered Framework for the design of gamified learning activities. This framework provides five-stage guidelines for applying GLT in instructional design: identification of learning activities that should be gamified, knowing the player and the learner type of users, designing gamified activities, performing fun learning sessions, and finally, the design evaluation. Even though the framework supports the development of user types (C2), its application and evaluation are needed to give a better understanding of the links between player and learner types $(\mathrm{C} 1)$.

In [10] authors investigated the impact that learner type based on Felder-Silverman Learning Style Model (FSLSM) and personality traits have on students' perception and performance in a gamified learning intervention. For the gamified intervention achievements, avatars, quests, teams, and virtual goods were integrated into different learning activities, after what a controlled experiment with 158 students was conducted. Their findings showed that "individuals who are orientated towards active or global learning have a positive impression of gamification" and "extraverts like gamification, while introverts are less motivated by it." However, their work does not provide any concrete guidance or framework for the gamification design, and thus, the contribution for $\mathrm{C} 2$ is not provided. 
Based on what has been presented in this section, it is not yet possible conclude how LTs influence gamification success and how GEs should be integrated in the learning to address the needs of different learner types. Therefore, by taking into account learners' LTs in the investigation of learners' engagement and attitudes towards gamified learning environments, this works aims to fulfill the gap. First, by introducing the background on LTs this work steps toward a better understanding of possible links between learner' types and GEs and thus contribute to the $\mathrm{C} 1$. Next, by leveraging implications derived from theories of LTs and gamification design principles into a model for personalized gamification we provide a strong basis for further research towards understanding how educational and personal aspects mediate and how that shapes the design of a gamified experience. Finally, the results derived from the PeGaM application and evaluation brings new insights on how learner types can be integrated into the personalized gamification, which contributes to $\mathrm{C} 2$.

\subsection{The four dimensions of learning tendencies}

LTs are "cognitive, affective, and psychological behaviors that serve as relatively stable indicators of how learners perceive, interact with, and respond to the learning environment" [6]. The concept of LTs originates from the classification of psychological types and is formed of cognitive, emotional, and environmental factors [11]. Various theories on learning LTs, such as MBTI [12], Kolb's theory [13], and FSLSM [14], are used in psychological and educational research. According to [14], LTs asserts individuals have preferences along four bipolar dimensions of learning: processing (how one tends to process new information), understanding (how one tends to progress towards the understanding of new information), perception (how one tends to perceive information), and presentation (which type of information an individual prefers). These bipolar dimensions are described as 'double-pan scales', where 'pans' present the two opposite poles (see Fig. 1). Which pan will weigh depends on the strength of the preference (mild, moderate, or strong) the student has toward a particular dimension' side. The stronger the tendency toward one side, the greater the chance that the student will resort to the 'more likely' behavior for that side of the dimension (e.g. student with a strong tendency towards visual perception will probably welcome learning materials in form of video/picture more than the one in form of a text/audiobook). The description of each polar dimension is shown in Table 2.

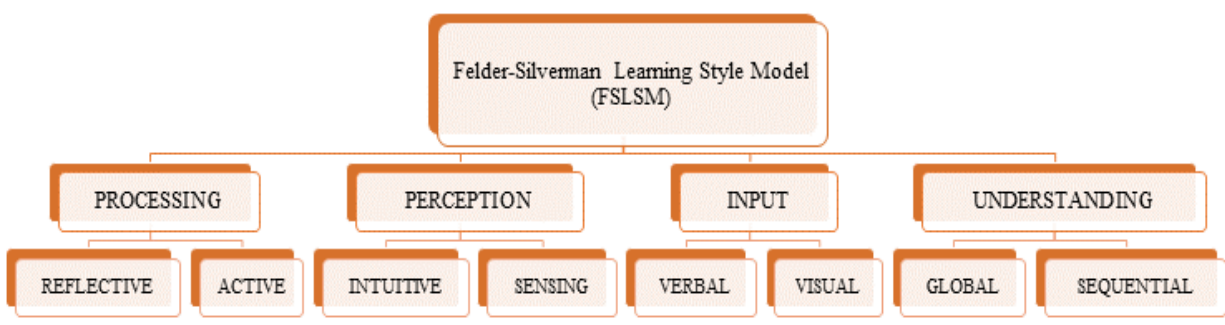

Figure 1. Left and right pole of the four learning dimensions from the FSLSM [6]

The underlying idea of LT's theories is that instructional design should be in line with learners' LTs to provide learners a possibility to fulfill their potential. However, in the light of the ongoing critical discussions about LTs and their miss-interpretation [15], this section defines what our work does (not) entail under the term 'LTs', and how LTs are (not) used in this study. First, LT describes learner's behavioral tendencies, not their behavior. If students are confronted with different learning situations they will tend to behave in a manner characteristic to their LT. Next, the four bipolar dimensions that shape LTs are seen as a spectrum, not as a category. LTs are not used as reliable indicators of learning outcomes and success. They are seen as indicators of learning strengths and weaknesses that certain LT is likely to have. Finally, the goal of identifying LTs is not "to label students and modify instruction to fit their labels", but to use what we know about LTs to create an effective and 
pag. 6

balanced learning environment. As the authors of the model say "balanced environment is one in which students are sometimes taught in a manner that matches their learning preferences, so they are not too uncomfortable to learn effectively, and sometimes oppositely, so they are forced to stretch and grow in the direction they might be inclined to avoid" [16]. From that viewpoint, authors appeal to instructors to get to know the LTs of their students and to modify the instruction to address students' needs. However, in the context of a gamified learning environment, PeGaM proposes a somewhat flipped perspective on how knowledge of LTs should be used. Namely, as the gamified learning theory implies, gamification does not affect learning directly but is rather used to stimulate learning-related behavior that can influence one's learning [17]. Thus, instead of instructors changing their teaching style, designers should change the gamification design in a way it addresses certain learning behavior. Fig. 2 visualizes how gamification intervention should affect learning behavior to produce balanced gamified intervention.
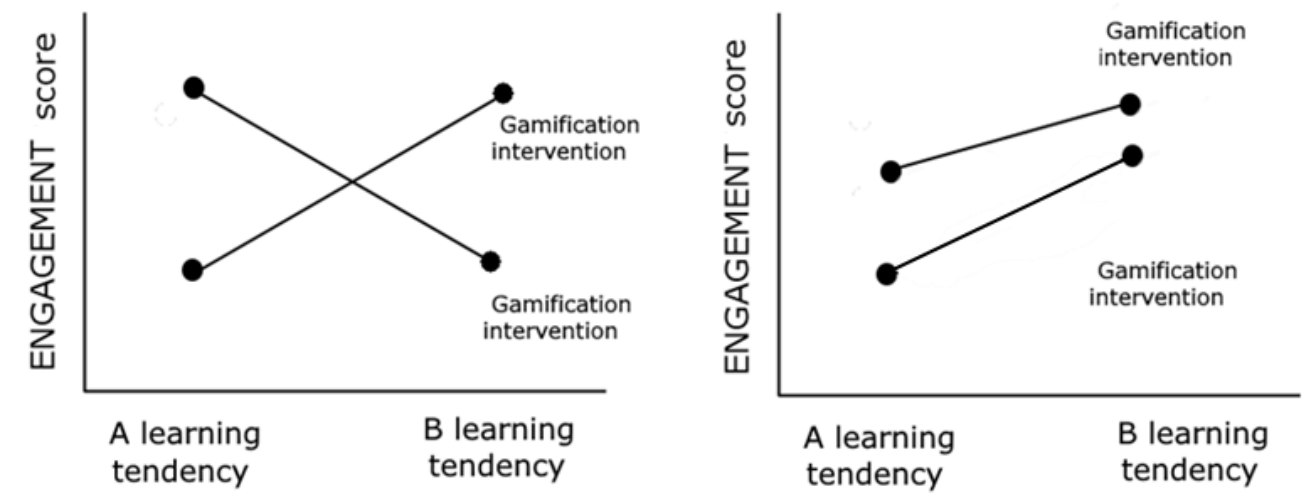

Figure 2. Misbalanced (left) and balanced (right) results of the gamification intervention, showing that balanced results are obtained only if the intervention manage to boost mean engagement scores of subjects in both LTs groups, having no crossover effects

In the remaining of the paper, we describe the PeGaM for the design of a UC gamification and present its' application.

\section{Personalized Gamification Design Model (PeGaM)}

The iterative PeGaM is created based on a design framework for a UC gamification proposed in [8]. The framework suggests five conceptual elements to be considered in applying UC (see Fig. 3.). The elements can be arranged in several design paths (logical orders in which the five elements should shape the design) based on a research area and targeted challenges. Below, we outline how we constructed these conceptual elements to design the iterative model for personalized gamification design. 


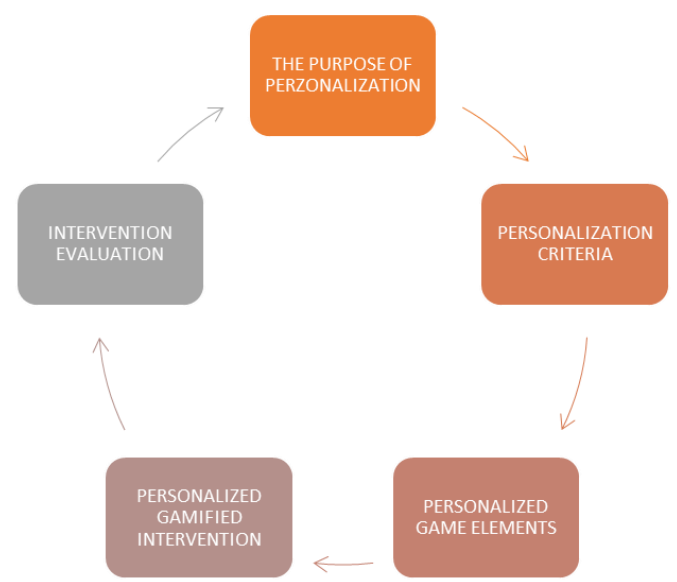

Figure 3. Design path for the PeGaM, adapted from [30]

The PeGaM application starts with the Purpose of personalization i.e. defining the statement on "What we want to achieve with personalized gamification?" (e.g. to boost users' engagement). The vital part of this stage is to clearly define desired outcomes and how accurately the goal achievement can be measured. Next, the Personalization Criteria implies end-user analysis to identify the motivation, needs, and preferences of future users. The criteria choice may depend on the system and the context (online, traditional), quality and quantity of available user information, data privacy regulation or the predefined purpose of intervention (e.g. if the purpose is to boost motivation then the data on individual motivation indicators could serve as criteria). Then, the designers of a gamified learning environment get to the selection of GEs that will be implemented. The selection should be performed in regard to the interest of the target group as well as the gamification purpose (e.g. a storyline may be suitable when the aim is to drive user behavior in certain, predefined directions [6]). Besides, the choice of GEs varies on the application domain and its' realworld constraints (e.g. if GEs are applied in the existing environment, it must be considered what is achievable in a certain time or for a certain environment). Finally, the decision should be supported by both the theoretical and empirical implications of the particular domain. Afterward, the Personalized Intervention questions "how should we incorporate those GEs, when and where?" This is the stage where selected GEs are integrated in such a way that they can help users reach the purpose that gamification aims to fulfill. Lastly, the effectiveness of the new implementations has to be analyzed and the results should be used to further improve a gamified environment.

\section{PeGaM in practice - the exploratory case setting}

The PeGaM is applied to create a balanced, gamified learning environment (the purpose of personalization) based on students' LTs (personalization criteria). The balance should reduce, and at the best, eliminate differences in students' perception and behavior in a gamified learning environment [18]. For this, gamification designers should provide a variety of experiences and engagement triggers (personalized GEs) to raise the chances that each student can find something meaningful (personalized intervention). To achieve this, designers need to understand the relationships between personalization criteria and GEs (in this case if and how LTs moderate the effects of gamification). In the absence of the corresponding knowledge and the lack of investigation on gamification design regarding LTs, this study presents the fundamental steps for using PeGaM to design a balanced gamified learning environment. Namely, this study investigates if LTs affect gamification outcomes. In other words, we explore whether LTs should be considered in the process of designing personalized gamification. For this, we designed an exploratory experiment and explored two research areas (RA). The first RA aims to describe how learners who have the 
pag. 8

same LTs behave in gamified versus non-gamified environment. For that, an exploratory experiment followed by a quantitative evaluation was conducted to answer two research questions (RQ):

- RQ-1.1 Are there any behavioural differences between students who have the same LTs but are attending two different variants (gamified or non-gamified) of a course?

- RQ-1.2 If yes (RQ-1.1), are these differences caused by the influence of the LT and/or the group to which students belong?

The second RA describes how learners behave in, and perceive a gamified learning environment. Through qualitative and quantitative evaluation of the treatment (gamified) group, this study aims to answer the following questions:

- RQ-2.1 Are there any behavioural differences between students in the treatment group who have different LTs?

- RQ-2.2 What are experiences and attitudes towards a gamified environment of students with certain LTs in the treatment group?

\subsection{Research context and design}

This study was realized through the creation of an online JavaScript (JS) for Bachelor Computer Science (CS) students, who registered for the "Web Technologies" course taught every winter semester at the RWTH Aachen University. Participation was voluntary, although, students had the opportunity to earn three bonus points as entry points for the Web technologies course. The JS course was organized online (October 2018 to April 2019.) within the Moodle LMS. The course consisted of six learning units covering a wide range of topics. Each unit had lecture notes, video recordings and practical coding examples, supplementary materials like books and links, and learning activities (quizzes, exercises, and coding challenges (exercises for which solutions are not provided)). The course was divided into two 'periods' - grading (GP) and non-grading (non-GP). During the GP, the first four units were opened, and students had the opportunity to earn bonus points by completing three assignments and quizzes on time. After the GP has passed, a non-GP started which opened two remaining learning units (V and VI). The complete course was available for three months. The course organization and design is presented in Fig. 4.

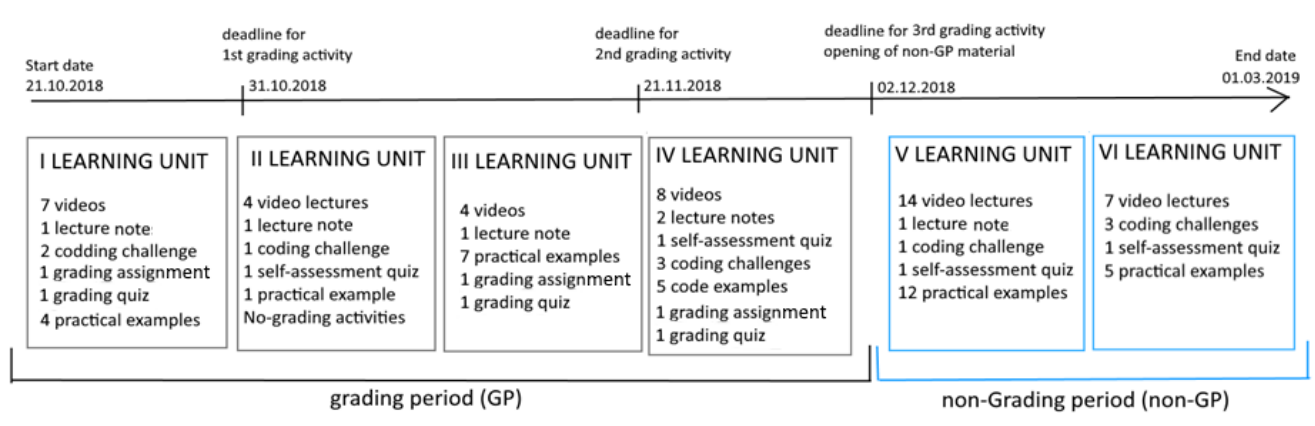

Figure 4. Course organization and design

During the study, participants were enrolled in the control (non-gamified) or the treatment (gamified) groups. The gamified and non-gamified versions of the course were the same concerning learning activities and materials except that the gamified version had game elements incorporated in the course. 


\subsection{The application of the PeGaM}

Personalization criteria. Considering the context of this study (e-learning) and its participants (CS students) PeGaM uses information on learners' LTs derived from FSLSM as personalization criteria. Namely, their model is recognized as the most suitable for the identification of LTs among engineering students in e-environments.

Personalized game elements. In this study, the selection of GEs starts from the intervention purpose - the list of commonly investigated elements concerning intended behavioral (users' online engagement) and psychological (users' perception) outcomes. Then, it narrows based on the available GEs in the Moodle LMS.

Table 1. GEs and corresponding psychological/behavioral outcomes

\begin{tabular}{|c|c|c|c|c|}
\hline \multirow[b]{2}{*}{$\begin{array}{l}\text { Most commonly } \\
\text { used GEs [19] }\end{array}$} & \multicolumn{2}{|c|}{ Intervention intention } & \multirow{2}{*}{$\begin{array}{c}\text { Available } \\
\text { in Moodle LMS } \\
\text { (real-world } \\
\text { constraints) } \\
{[20]}\end{array}$} & \multirow[b]{2}{*}{ Final GEs list } \\
\hline & $\begin{array}{l}\text { Behavioral } \\
\text { outcomes }\end{array}$ & $\begin{array}{l}\text { Psychological } \\
\text { outcome }\end{array}$ & & \\
\hline Badges & $\mathrm{x}$ & $\mathrm{x}$ & $\mathrm{x}$ & $\mathbf{x}$ \\
\hline Leaderboards & $\mathrm{x}$ & $\mathrm{x}$ & $\mathrm{x}$ & $\mathbf{x}$ \\
\hline Points and Levels & $\mathrm{x}$ & $\mathrm{x}$ & $\mathrm{x}$ & $\mathbf{x}$ \\
\hline Progress Bar & $\mathrm{x}$ & $\mathrm{x}$ & $\mathrm{x}$ & $\mathbf{x}$ \\
\hline Goals & $\mathrm{x}$ & & & \\
\hline $\begin{array}{l}\text { Rewards/Virtual } \\
\text { Goods }\end{array}$ & $\mathrm{x}$ & $\mathrm{x}$ & & \\
\hline Narrative & $\mathrm{x}$ & $\mathrm{x}$ & & \\
\hline Feedback & & $\mathrm{x}$ & $\mathrm{x}$ & \\
\hline Unlockable content & $\mathrm{x}$ & & $\mathrm{x}$ & \\
\hline Teams & & $\mathrm{x}$ & & \\
\hline
\end{tabular}

As presented in Table 1, the selected GEs for this study are badges, leaderboards, experience points (XPs), and progress bars. Badges are virtual elements, that can be owned by a player. They consist of a graphical symbol that should be visually appealing to the player and gets displayed on his/her profile page. In most cases, the player earns badges as a reward for reaching a goal of achieving good performance. Levels are a progression of different states which the user passes during the game. They are used to visualize learning progress to the user. These are often designed in such a way that the initial levels require less effort and are faster to achieve while the advanced levels require more effort and skills. A leaderboard is a list of players ordered by their points. It is used to show players' process. The social comparison between the players leads to a competitive dynamic between the users and raises motivation. Progress bars are visualizations of the progress a learner has made. They can be used to further motivate players who are close to achieving a learning goal or when they are falling behind in its progress [21]

These elements, together known as the PBL system (Points, Badges, and Leaderboards) are the commonly used GEs, but also one of the most debatable. Namely, while some report their positive influence, others report neutral or negative influence on behavioral and psychological outcomes [22]. Because of these contradictions we consider PBL as a good starting point for the primary research, as there is no exploration of PBL concerning LTs. With this, our study contributes new knowledge on understanding PBL in a UC gamification environment.

Personalized gamified intervention. Once the GEs are selected, designer needs to investigate where and how these elements can be incorporated in the system. For that, we first identified system activities that can be tracked and correlated with learners' description (the "where"). This was done based on the common activities used in studies investigating students' online behavior regarding LTs derived from the FSLSM [23]. Next, we gamified those activities with the usage of the previously selected GEs. With this, we can explore learners' LTs with their tendencies toward gamified actions and identify what is relevant 
pag. 10

for each. In Table 2, we briefly describe LTs as well as the corresponding learning and gamified activities.

Table 2. Learning dimensions in relation to their corresponding learning and gamification activities

\begin{tabular}{|c|c|c|c|}
\hline $\begin{array}{c}\text { Learning } \\
\text { dimensions }\end{array}$ & LTs & Moodle activities & Gamified activities \\
\hline $\begin{array}{l}\text { Processing - } \\
\text { How a student } \\
\text { tends to } \\
\text { process a new } \\
\text { information? }\end{array}$ & $\begin{array}{l}\text { By interacting } \\
\text { with other people } \\
\text { and trying } \\
\text { something new } \\
\text { (active) or by } \\
\text { working alone, } \\
\text { and thinking } \\
\text { about new } \\
\text { information } \\
\text { before trying it } \\
\text { out (reflective)? }\end{array}$ & $\begin{array}{ll}\text { - } & \text { Forums } \\
\text { - } & \text { Time spent in course } \\
\text { - } & \text { Course visits } \\
\text { - } & \text { Knowledge- } \\
\text { assessment tasks }\end{array}$ & $\begin{array}{l}\text { - Earn XP's for exploring } \\
\text { the course } \\
\text { - } \quad \text { Offer a badge for } \\
\text { sharing knowledge and } \\
\text { actively participating in } \\
\text { discussions } \\
\text { - Show student' progress } \\
\text { on a leader board }\end{array}$ \\
\hline $\begin{array}{l}\text { Perceiving - } \\
\text { How a student } \\
\text { tends to } \\
\text { perceive and } \\
\text { take new } \\
\text { information? }\end{array}$ & $\begin{array}{l}\text { Thinking about } \\
\text { concepts and } \\
\text { theories } \\
\text { (intuitive) or } \\
\text { taking facts and } \\
\text { data in a well- } \\
\text { established } \\
\text { procedure } \\
\text { (sensing)? }\end{array}$ & $\begin{array}{l}\text { - Visits to examples } \\
\text { and solutions } \\
\text { - Visits to } \\
\text { abstract/theoretical } \\
\text { materials }\end{array}$ & $\begin{array}{l}\text { Offer badges for doing } \\
\text { coding challenges }\end{array}$ \\
\hline $\begin{array}{l}\text { Understanding } \\
\text { - How a } \\
\text { student tends } \\
\text { to process } \\
\text { towards an } \\
\text { understanding } \\
\text { of new } \\
\text { information? }\end{array}$ & $\begin{array}{l}\text { Learning } \\
\text { sequentially } \\
\text { (sequential), or } \\
\text { creating his/her } \\
\text { holistic learning } \\
\text { path (global)? }\end{array}$ & $\begin{array}{l}\text { Action distribution } \\
\text { (through time) } \\
\text { Time distribution } \\
\text { (through days, weeks, } \\
\text { teaching units etc.) }\end{array}$ & $\begin{array}{l}\text { - Student can progress } \\
\text { through levels in the } \\
\text { course } \\
\text { - Show individual } \\
\text { progress on a progress } \\
\text { bar }\end{array}$ \\
\hline $\begin{array}{l}\text { Presentation - } \\
\text { Which style of } \\
\text { information } \\
\text { do students } \\
\text { tend to } \\
\text { access? }\end{array}$ & $\begin{array}{l}\text { Videos, chart } \\
\text { graphs (visual), } \\
\text { or books, and } \\
\text { texts (verbal)? }\end{array}$ & $\begin{array}{l}\text { Visits to materials } \\
\text { like videos and } \\
\text { graphs } \\
\text { Visits to books, } \\
\text { script, lectures } \\
\text { - Forums }\end{array}$ & $\begin{array}{l}\text { - Give XPs for accessing } \\
\text { various learning } \\
\text { materials }\end{array}$ \\
\hline
\end{tabular}

Badges represented accomplishments and were correlated with the assessments tasks, which were realized through assignments, quizzes, and exercises. Assignments and quizzes were graded (for the bonus points), while exercises were optional. The criteria for earning badges are shown in Table 3. Students could see their current badge "wallet" at any time, by accessing the 'badge listing view' page in the course. In total students could earn seven badges: five related to bonus tasks and two for completing additional exercises. 
Table 3. Badge descriptions shown on a 'Badge listing view' page

\begin{tabular}{|c|c|c|c|}
\hline Name & Image & Description & Awarding criteria \\
\hline JS Student & $\begin{array}{c}\text { Is } \\
\text { STUDENT }\end{array}$ & $\begin{array}{c}\text { You have the necessary knowledge to } \\
\text { progress and become a good JS } \\
\text { programmer! }\end{array}$ & $\begin{array}{c}\text { First grading activity } \\
\text { submitted on time }\end{array}$ \\
\hline $\begin{array}{c}\text { JS } \\
\text { Intermediate }\end{array}$ & $</>\overline{5}$ & $\begin{array}{c}\text { JavaScript is becoming your friend! You } \\
\text { revealed some of the biggest secrets of JS! }\end{array}$ & $\begin{array}{c}\text { Second grading } \\
\text { activity submitted on } \\
\text { time }\end{array}$ \\
\hline JS DOM & DOM & $\begin{array}{c}\text { This badge represents your competencies } \\
\text { for working with DOM and Regular } \\
\text { Expressions! }\end{array}$ & $\begin{array}{c}\text { Coding challenge } \\
\text { submitted }\end{array}$ \\
\hline
\end{tabular}

Levels, XPs and leaderboard were associated and represented effort and participation. All actions, such as course and lecture visits, video watching, assignment submissions, etc. carried a certain amount of XPs, so students could level up by collecting them (see the right side of Fig. 5). By leveling up, students could open new exercises or alternative paths for accessing additional learning materials. Besides, students could see their current level and amount of XP's as well as their position on a leaderboard rank (see the left side of Fig. 5). These features were realized with the Moodle Level UP! Plugin [24].

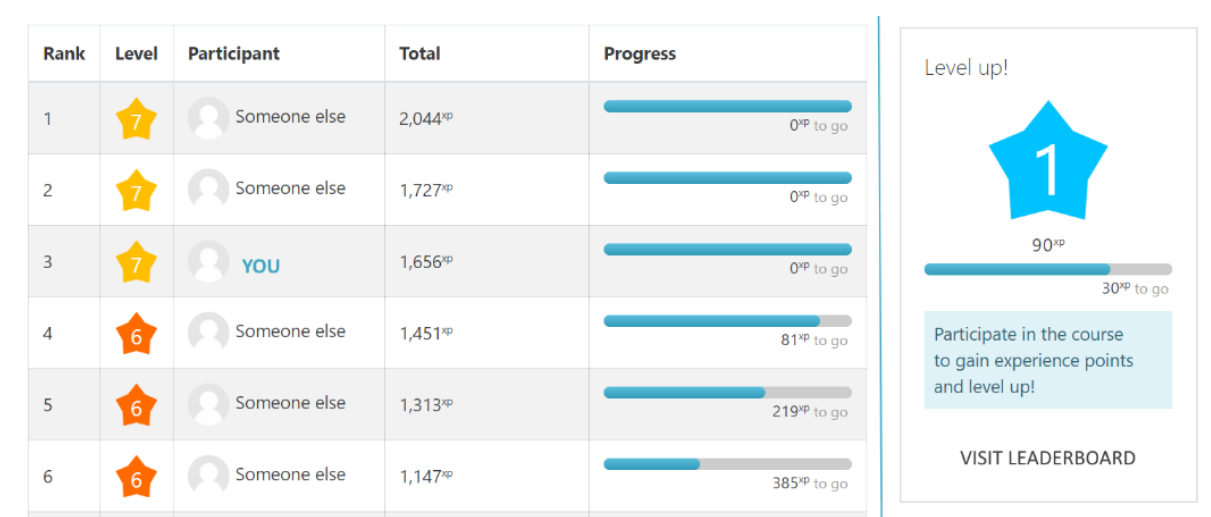

Figure 5. The student view of leaderboards (left) and the Leveling system (right) displayed in the course page

Lastly, the progress bar served as feedback for students to reflect on their completion rate. The progress bar showed the completion status of course activities. Completed ones were colored green, upcoming blue and failed tasks were marked with red color (see Fig. 6.).

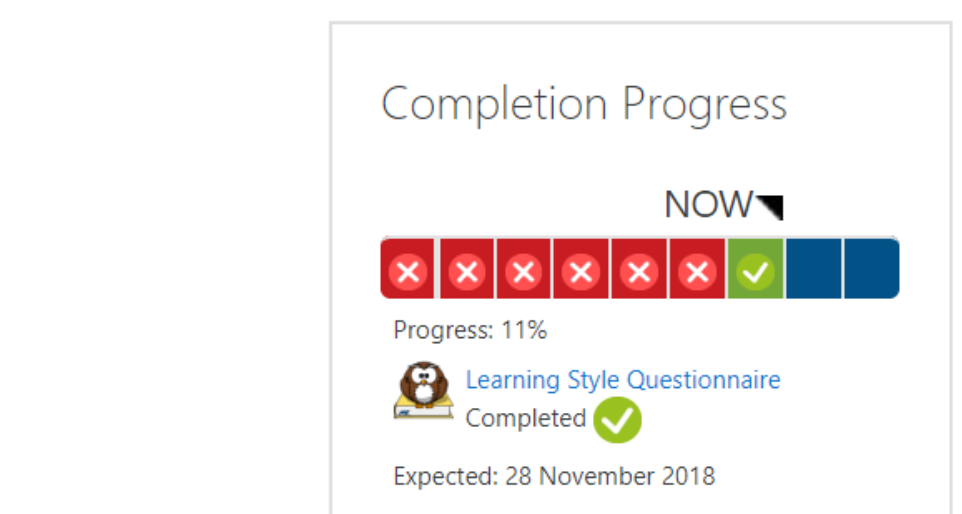

Figure 6. Student view of a progress bar, displayed on the right side of the course page 
pag. 12

\subsection{Data and feedback collection}

In this study, we adopted a mixed research method approach known as the sequential exploratory design method [25]. This method comprises a quantitative phase followed by a qualitative one. Thus, we collected data on students LTs and their activities taken within the Moodle LMS (quantitative), and a survey was conducted to reflect on the numerical results (qualitative). In total, we collected three sets of data.

The first set refers to data on ones LTs. For this, we developed a Moodle plugin [26], which integrates the original Index of Learning Style (ILS) questionnaire and saves the results into the Moodle databases. ILS is a self-scoring web-based instrument for measuring ones' LTs [27]. The test results in four numbers which present the tendency, where number $( \pm) 1$ and 3 show mild, $( \pm) 5$ and 7 moderate and $( \pm) 9$ and 11 strong tendencies to one or the other pole. Sign (+ or -) refers to the left or right extreme on the dimension' scale. The ILS test was given at the beginning of the course.

The next data set is on students' behavioral engagement. Broadly defined, behavioral engagement refers to active participation and immersion in a task [28]. Those tasks can be any social, academic, or extracurricular activity that, if taken, can lead to a positive academic outcome. As this course is a purely online part of the Web technologies course, students' behavioral engagement is measured based on their online activities in the course. To track and log online engagement data in regard to students' LTs we developed another plugin called Integrated Learning Style Analytic (ILSA) [29]. ILSA uses Moodle event storage and data on LTs to track learners' activities in the course (e.g. Student with 'id=2, and LTs="-1, 5, 3, 7" submitted assignment with 'id'=6). The collected data are shown in the teachers' dashboard (see Fig. 7).
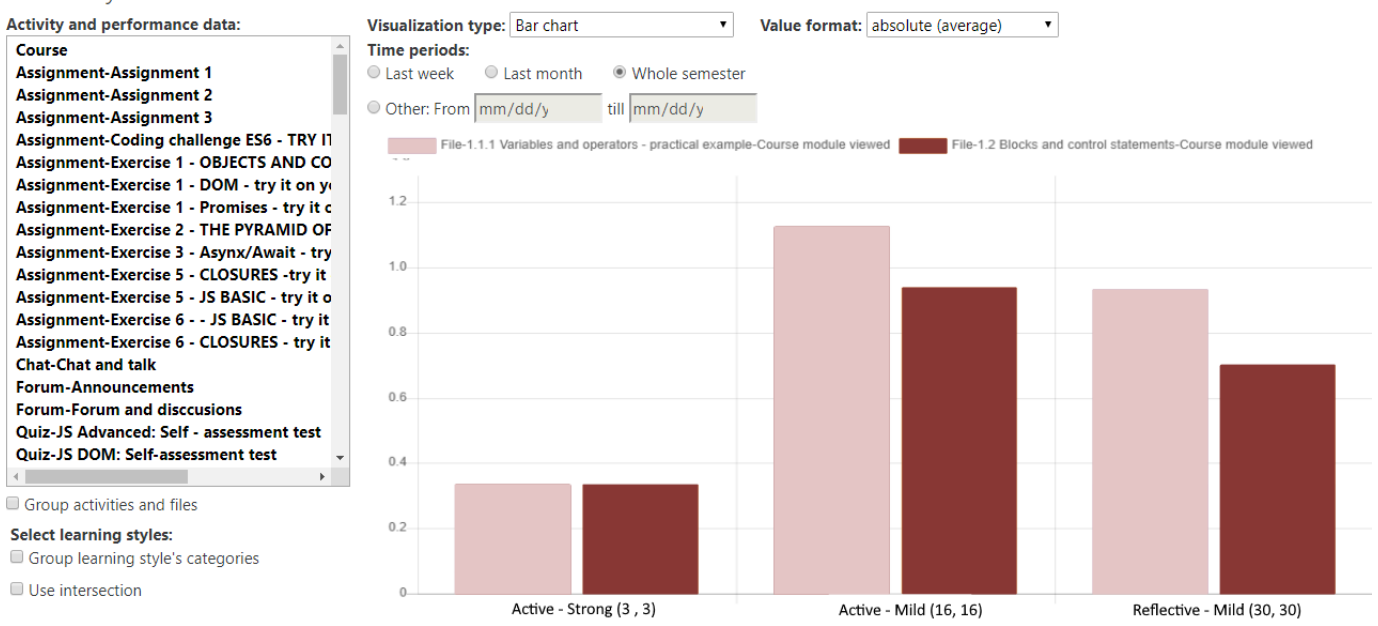

Figure 7. Teacher's view of the ILSA plugin, in which each Moodle activity is logged and correlated with students LTs [28]

Lastly, for addressing students' perceptions, an evaluation survey was given to each participant at the end of the course. Finally, Table 4 summarizes the data used to investigate our RAs. 
Table 4. List of data sets available for each student in the course

\begin{tabular}{|c|c|c|}
\hline & $\begin{array}{c}\text { Research } \\
\text { area }\end{array}$ & Data set \\
\hline LTs & RA $1 \& 2$ & $\begin{array}{l}\text { ILS results in form of four (e.g. processing: 1, perception: } 5 \text {, } \\
\text { presenting }-7 \text {, and understanding: } 11) \text {. }\end{array}$ \\
\hline Perception & RA 2 & Evaluation survey data \\
\hline \multirow[t]{2}{*}{$\begin{array}{l}\text { Online } \\
\text { behavioral } \\
\text { engagement }\end{array}$} & RA $1 \& 2$ & $\begin{array}{l}\text { Time related data } \\
\text { - Time spent in the GP and non-GP } \\
\text { - Time distribution (per sessions) } \\
\text { Activity related data } \\
\text { - Number of actions in GP and non-GP } \\
\text { - Action distribution (per sessions) } \\
\text { - Course visits in GP and in non-GP } \\
\text { Assessment related data } \\
\text { - Number of completed grading tasks } \\
\text { - Number of completed non-grading tasks } \\
\text { Learning materials related data } \\
\text { Visits to: videos, lecture notes, additional material- links, books, } \\
\text { practical example downloads - solutions }\end{array}$ \\
\hline & RA 2 & $\begin{array}{l}\text { Gamification related data } \\
\text { - No. of badges earned } \\
\text { - Access to the 'Badge listing view' page } \\
\text { - No. of collected XPs and level reached }\end{array}$ \\
\hline
\end{tabular}

\section{Results and discussion}

This study gathered 124 Bachelor CS students from the RTWTH Aachen University. All data extracted were analyzed using the IBM SPSS tool [30]. Based on the assessment of the data normality, parametric (Independent t-test, ANOVA, and two-way ANOVA) or nonparametric (Man Whitney U and Kruskal-Wallis) were used. The significance is measured at a level of $5 \%$ (p-value<.05) [31].

We started the inquiry by conducting a descriptive analysis (DA) on engagement data of students from control and treatment groups (see Table 5). The analysis showed that in the majority of cases, SDs were high. This can point to the statistical outliers that are seen as potential threats to data integrity or as a potential distortion of estimates of central tendency [32]. In these cases, dropping it out from the sample or transforming their value are suggested approaches for handling the outliers. However, in the field of education, it has been shown that outliers should not be seen as threats but rather as 'success stories'. As discussed in [33] due to the heterogeneity of learners in online environments outliers are to be seen as "normal occurrence". As of, we kept the students with high values as they are considered to be students with a high engagement rate rather than disrupting outliers.

Results showed (Table 5) students spent approximately 9 to 10 hours in the course (M $=554.38, \mathrm{SD}=493.00$ in the control, $\mathrm{M}=586.22, \mathrm{SD}=343.73$ in the treatment group), mostly during the GP. Specifically, 24/65 (37\%) from control and 23/59 (39\%) from the treatment group stopped accessing the course after the GP was over. Regarding their time in the course, it was observed that students were most active around the grading activity deadlines (see the right side of Fig. 8). Regarding the assessment activities, the majority of students completed all (2/3 or $3 / 3)$ grading tasks, while the completion rate is much less for the self-assessment activities. As for the learning materials, the most visited were additional materials and lecture notes, followed by videos and practical code examples. 
Table 5. Descriptive statistics of the data used in study

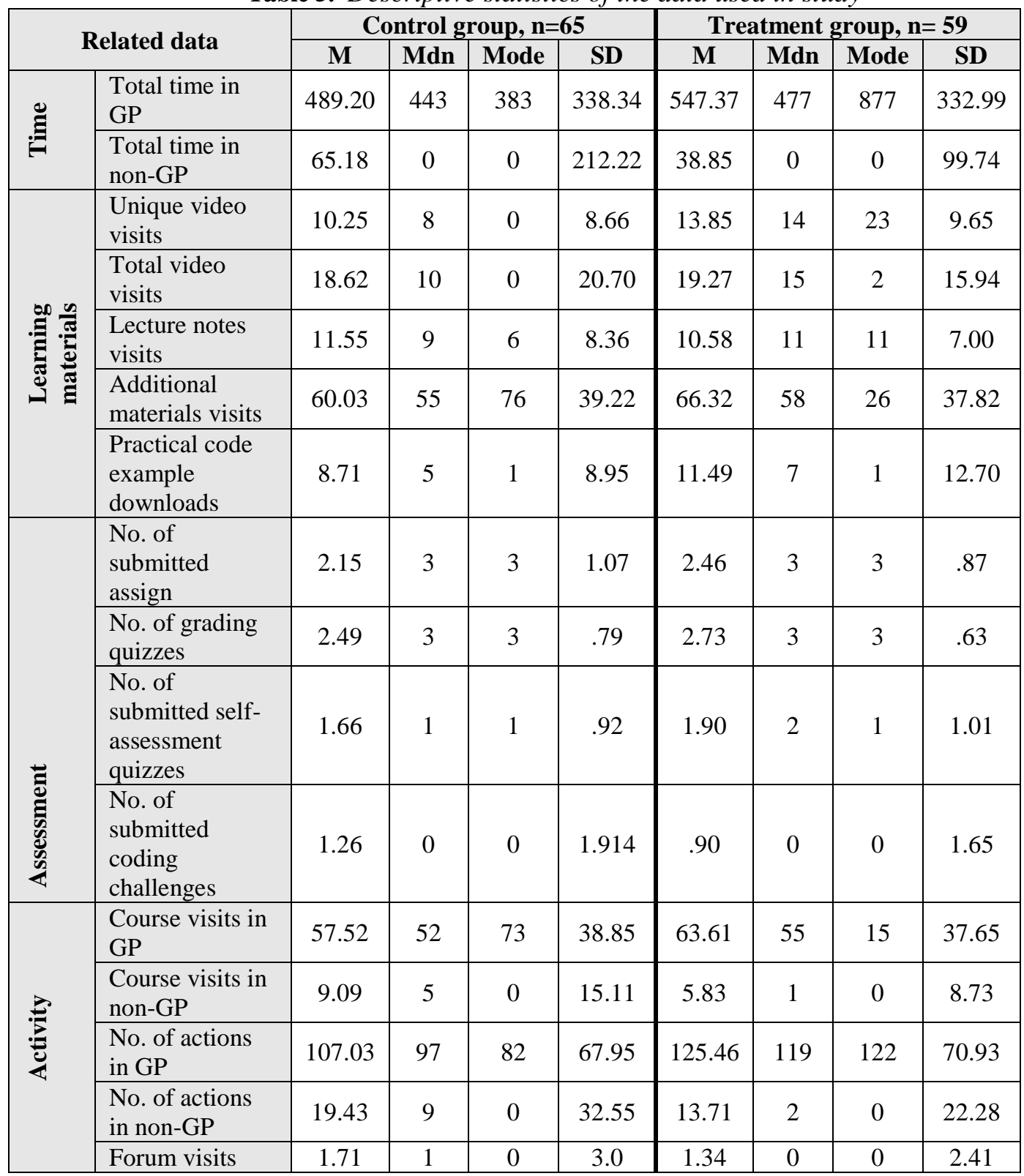

The distribution of time spent in course over sessions

Action distribution over time sessions
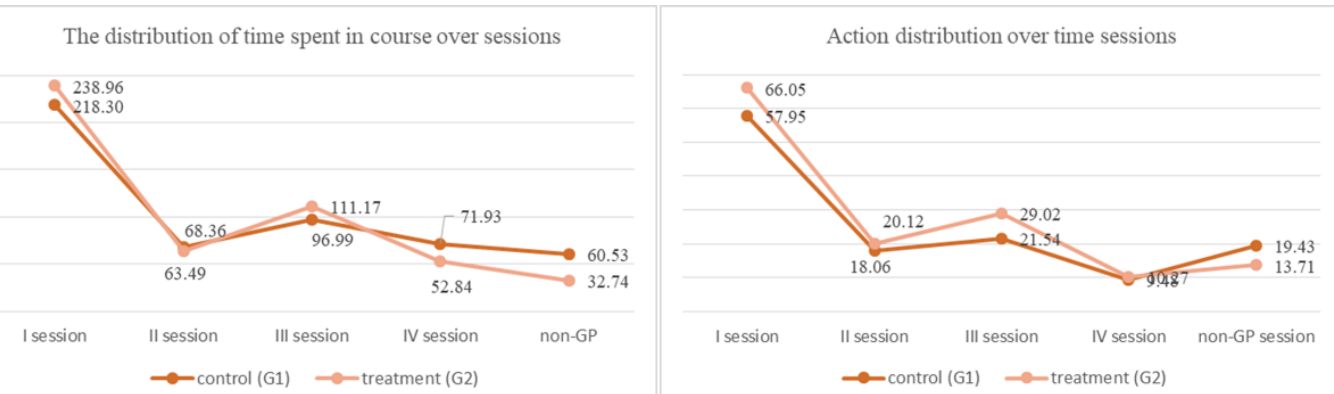

Figure 8. Mean engagement scores for control and treatment group

In the next step, we seek the potential statistical differences in behavioral engagement among students in two groups. The Mann-Whitney $U$ test showed median unique video visits score was significantly higher in the treatment (14.00) than in the control group (8.00), $\mathrm{U}=1523.5, \mathrm{z}=-1.972, \mathrm{p}=.024$. In addition, median visits to additional resources score 
was significantly higher in the treatment (65.00) than in the control (54.00), $\mathrm{U}=1467, \mathrm{z}=$ $-2.258, \mathrm{p}=.049$. There were no statistical differences for other behavioral data $(\mathrm{p}>0.05)$.

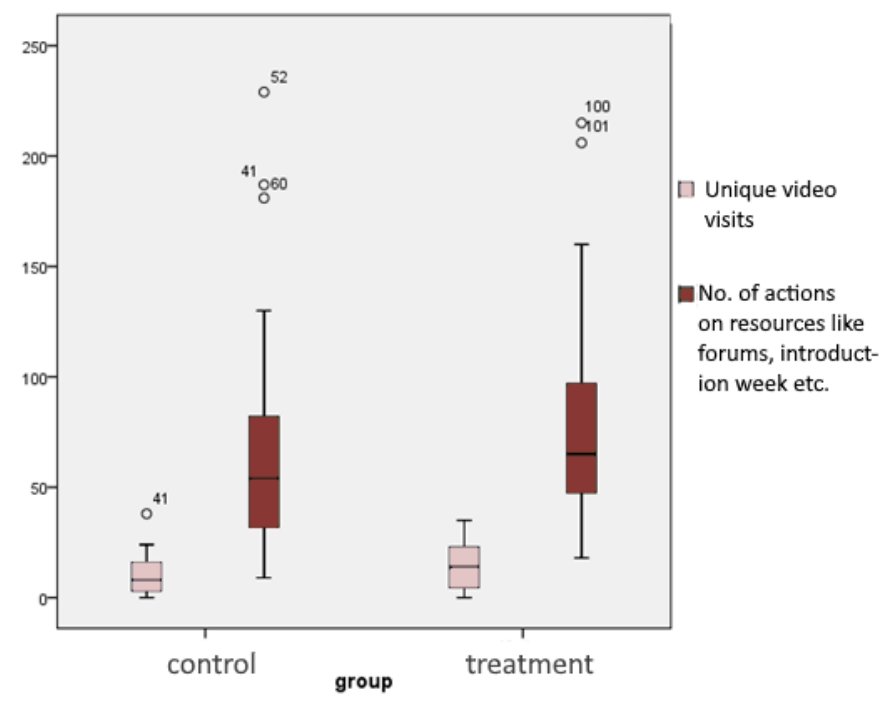

Figure 9. Statistical differences between control and treatment group

After comparing the general behavior of students within the two groups, the remaining sections discuss the conducted investigation of two RAs, in which participants are grouped based on their LTs.

\subsection{Research area 1: Behavioral engagement analysis of students in regard to their LTs}

As stated in the literature [21], students aspire to a particular learning behavior. Thus, RA1 questions if students with the same LTs behave differently when exposed to different learning environments (gamified and non-gamified), and, if yes, are the behavioral differences caused by the effect of learning dimension and group affiliation. For this, two hypotheses are set:

- H1: There is a behavioral difference between students (who have the same LTs) in the gamified and non-gamified group.

- H2: Both LTs and group affiliation influence students' behavior in the course.

The hypotheses are tested for each LT (e.g. comparing the behavior of students with tendencies towards reflective learning in control versus treatment group). The statistical results together with DA concerning data of interest are discussed below. Fig. 10 shows the distribution of LTs in each group. The distribution in which the majority of students have active, sensing, visual, and sequential LTs is a common distribution among engineering classes [26].

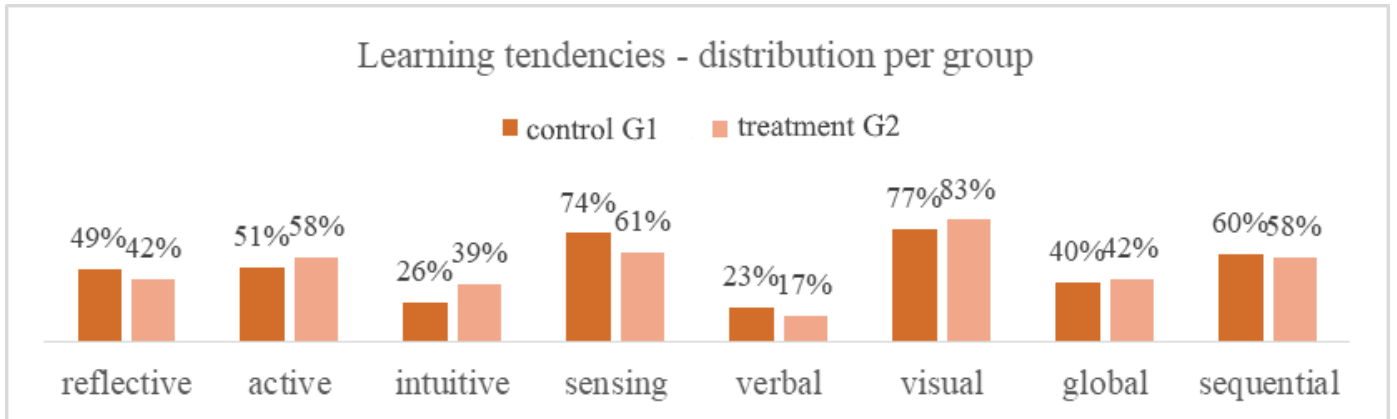

Figure 10. Learning tendencies distribution 


\subsubsection{Processing learning dimension}

The processing dimension describes how learners seek to process new information. Active students prefer group work and participation in a sense of "let's try something out", while reflective students are more introspective. They prefer to work alone and invest time in thinking before they act. As of, special attention in the analysis of their behavior was paid to data regarding the time they spent in the course, the number of actions taken, and the number of completed knowledge-assessment tasks. Table 6 shows significant differences in the behavior of reflective students between groups obtained by the Man Whitney U test.

Table 6. Man Whitney $U$ test results, significant differences between reflective students in control and treatment

\begin{tabular}{|c|c|c|c|c|c|}
\hline Behavioral data & $\begin{array}{c}\text { Mdn } \\
\text { control } \\
\text { group, } \mathbf{n = 3 2}\end{array}$ & $\begin{array}{c}\text { Mdn } \\
\text { treatment } \\
\text { group, } \mathbf{n = 2 5}\end{array}$ & $\mathbf{U}$ & $\mathbf{Z}$ & $\mathbf{p}$ \\
\hline Time spent in first session & 219.0 & 334.0 & 277.5 & -1.970 & $\mathbf{. 0 4 9}$ \\
\hline No. of unique video visits & 7.0 & 21.0 & 213.5 & -3.009 & $\mathbf{. 0 0 3}$ \\
\hline No. of total video visits & 9.0 & 25.0 & 277.0 & -1.981 & $\mathbf{. 0 4 8}$ \\
\hline $\begin{array}{c}\text { No. of submitted self- } \\
\text { assessment quiz }\end{array}$ & 1.0 & 2.0 & 258.0 & -2.467 & $\mathbf{. 0 1 4}$ \\
\hline $\begin{array}{c}\text { No. of total actions in GP } \\
\text { No. of visits to additional } \\
\text { resources }\end{array}$ & 82.0 & 151.0 & 273.0 & -2.043 & $\mathbf{. 0 4 1}$ \\
\hline
\end{tabular}

\subsubsection{Perception learning dimension - intuitive and sensing LTS}

Students with sensing LTs prefer to learn concrete materials like formulas and algorithms, while intuitive like to explore new ways of learning and are more oriented towards abstract materials. In this regard, DA was performed on data regarding visits to different learning materials and self-assessments tasks (Fig. 11).

Table 7. The two-way ANOVA results with 'time spent in GP' as dependent variable

\begin{tabular}{|c|c|c|c|c|c|c|}
\hline Factor A & Factor B & Mean & SD & N & $\begin{array}{c}\text { Confidence interval } \\
(\text { CI })\end{array}$ & MD \\
\hline \multirow{3}{*}{ Control group } & mild intuitive & 356.60 & 261.28 & 10 & {$[144.90,568.77]$} & -315.97 \\
\cline { 2 - 7 } & $\begin{array}{c}\text { strong } \\
\text { sensing }\end{array}$ & 729.62 & 510.36 & 8 & {$[492.94,966.8930$} & +444.37 \\
\hline \multirow{2}{*}{$\begin{array}{c}\text { Treatment } \\
\text { group }\end{array}$} & \begin{tabular}{c} 
mild intuitive \\
\cline { 2 - 7 }
\end{tabular} & 672.57 & 434.27 & 14 & {$[498.31,846.82]$} & +315.97 \\
\hline $\begin{array}{c}\text { strong } \\
\text { sensing }\end{array}$ & 285.25 & 470.15 & 4 & {$[40.74,611.24]$} & -444.37 \\
\hline
\end{tabular}

Concerning the $\mathrm{H} 1$ an independent t-test showed intuitive students in the treatment group had statistically more downloaded code examples $(\mathrm{M}=12.43, \mathrm{SD}=14.03), \mathrm{t}(38)=-$ 2.440, $\mathrm{p}=0.022$, compared to intuitive students in the control $(\mathrm{M}=4.88, \mathrm{SD}=4.152)$. Regarding the $\mathrm{H} 2$, a two-way ANOVA showed a significant interaction effect of group and perception dimension on the time spent in $\mathrm{GP}, \mathrm{F}(5,124)=2.490, \mathrm{p}=.035, \eta \mathrm{p} 2=.10$. There was a significant difference in mean scores for mild intuitive students $\mathrm{F}(1,112)=5.345$, 
$\mathrm{p}=.023, \eta \mathrm{p} 2=0.046$, as for the strong sensing students $\mathrm{F}(1,112)=4.833, \mathrm{p}=0.03, \eta \mathrm{p} 2=0.041$. Table 7 shows the descriptive statistics of data used in two-way ANOVA.

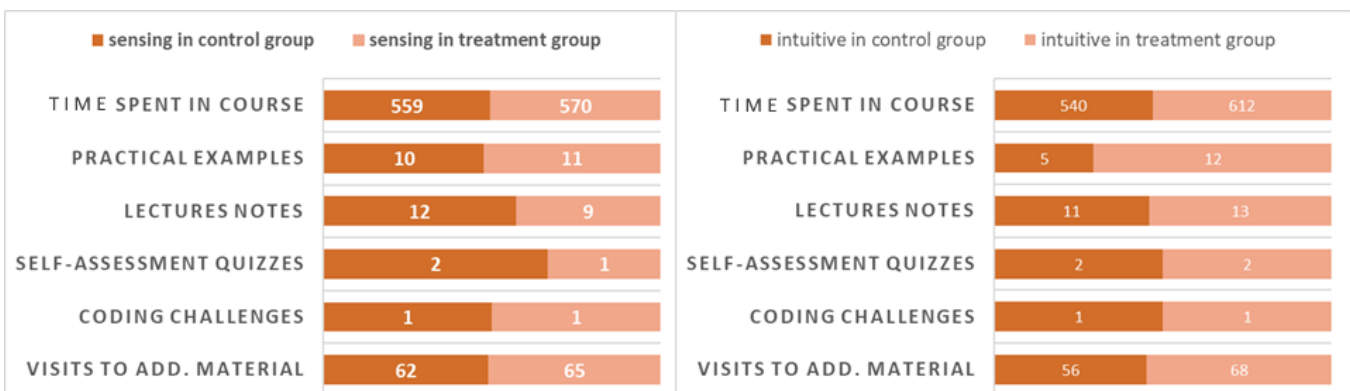

Figure 11. Mean engagement score of sensing and intuitive students

Further, there was a significant group and perception dimension interaction effect on the number of unique video visits $\mathrm{F}(5,112)=2.437, \mathrm{p}=.039, \eta \mathrm{p} 2=.098$. There was a significant difference in mean scores for mild intuitive students $\mathrm{F}(1,112)=6.432, \mathrm{p}=.013, \eta \mathrm{p} 2=0.054$, as for moderate sensing students $F(1,112)=6.280, p=0.014, \eta p 2=0.053$. Table 8 and Fig. 12 show, respectively, the descriptive statistics and visual presentation of data used in twoway ANOVA.

Table 8. The two-way ANOVA results with 'unique video visits' as dependent variable

\begin{tabular}{|c|c|c|c|c|c|c|}
\hline Factor A & Factor B & Mean & SD & $\mathbf{N}$ & $\begin{array}{c}\text { Confidence interval } \\
(\mathbf{C I})\end{array}$ & MD \\
\hline \multirow{2}{*}{ Control group } & mild intuitive & 8.5 & 6.06 & 10 & {$[3.297,13.70]$} & -10.40 \\
\cline { 2 - 7 } & $\begin{array}{c}\text { moderate } \\
\text { sensing }\end{array}$ & 13.17 & 6.59 & 6 & {$[3.975,10.692]$} & +6.71 \\
\hline \multirow{2}{*}{$\begin{array}{c}\text { Treatment } \\
\text { group }\end{array}$} & \begin{tabular}{c} 
mild intuitive \\
\cline { 2 - 7 }
\end{tabular} & 17.79 & 11.13 & 14 & {$[12.70,22.87]$} & +10.17 \\
\hline
\end{tabular}

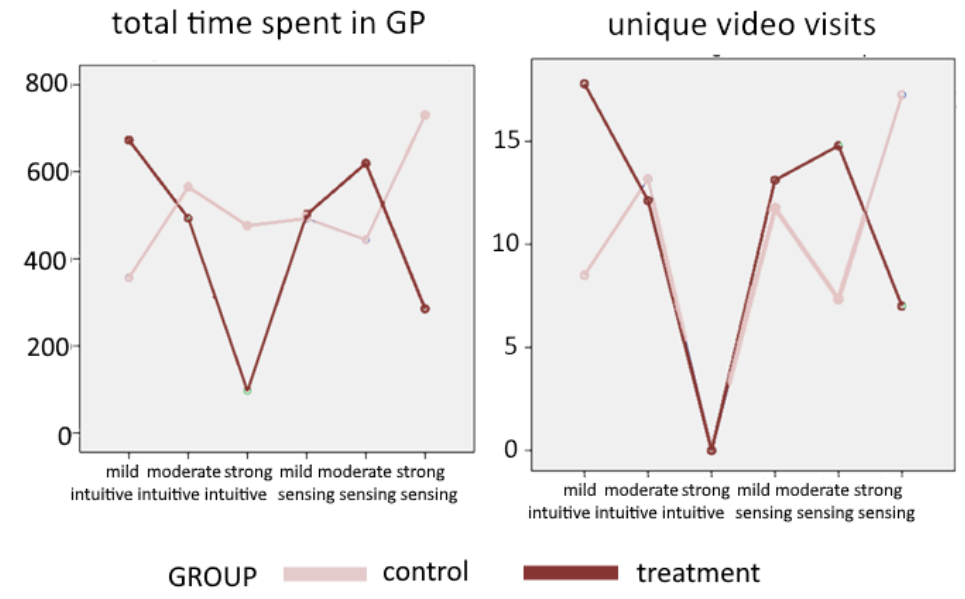

Figure 12. Results of the two-way ANOVA test

\subsubsection{Presentation learning dimension - verbal and visual}

Visual students prefer materials presented as pictures, graphs, and videos, unlike verbal who are more comfortable with written and oral words. In this regard, Fig. 13 shows DA of 
pag. 18

data regarding their visits to different learning materials. Man Whitney $U$ test showed unique video visits of visual students were significantly higher in the treatment (15.0) than in the control (8.0) group, $\mathrm{U}=894.00, \mathrm{z}=-2.321, \mathrm{p}=.020$. No behavioral difference was noted for verbal students.

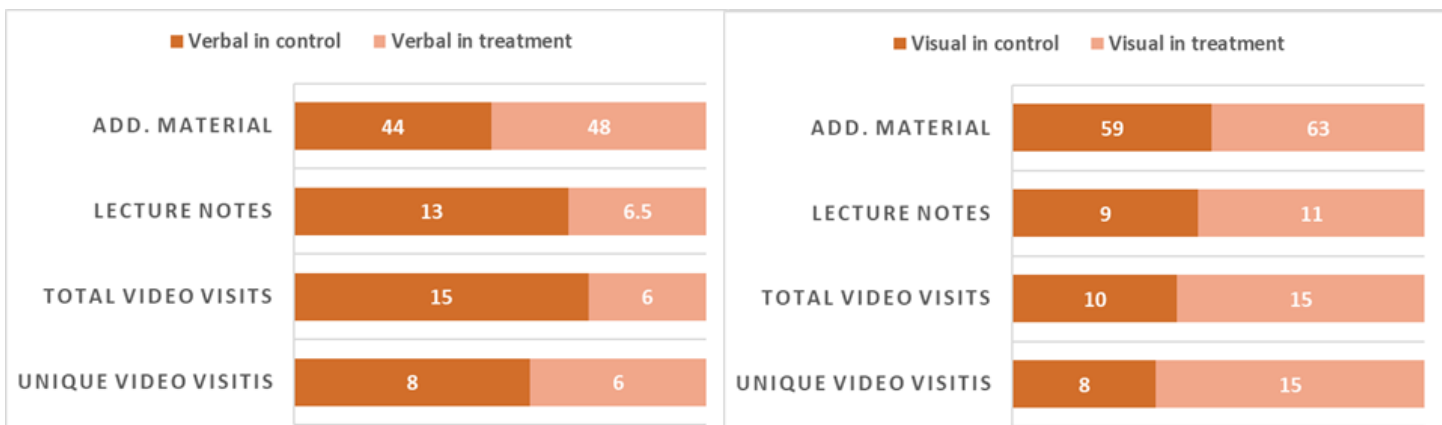

Figure 13. Median of No. of visits to different learning materials for visual and verbal students

\subsubsection{The dimension of understanding - global and sequential LTS}

This dimension describes how learners progress towards understanding information. Sequential students have linear progress, with an approach increasing in complexity, while global tend to digest materials, not realizing any connection initially and rather suddenly grasp the meaning. In this regard, Fig. 14 shows their time and action distribution in the course.

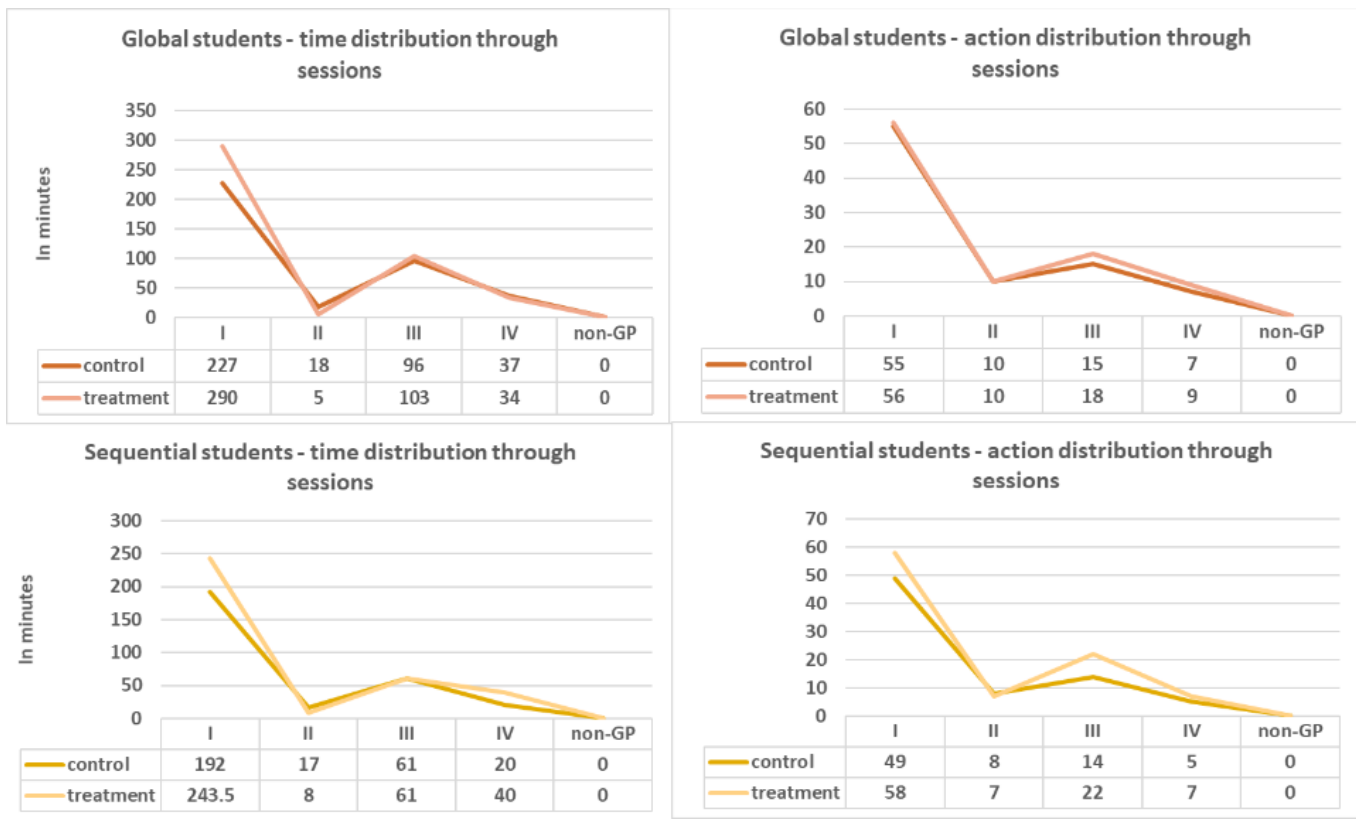

Figure 14. The distribution of time spent in the course and actions taken during that time for global and sequential students

The independent t-test showed global students from the treatment $(\mathrm{M}=80.84$, $\mathrm{SD}=44.69)$ had statistically more number of visits to other resources, $\mathrm{t}(49)=-2.187, \mathrm{p}=0.034$ compared to their peers in the control $(\mathrm{M}=58.39, \mathrm{SD}=25.902)$ group. For sequential students, no statistical differences were found.

Overall, the statistical difference in behavior was noted in the case of reflective, visual, intuitive, sensing and global students, thus, the $\mathrm{Hl}$ is partly accepted. Further, the influence of group affiliation and learning dimension was noted for the perception dimensions, hence, the $\mathrm{H} 2$ is partially accepted. 


\subsection{RA-2: Investigation of students' behavior in and perception of gamified environment}

In this RA, the analysis is conducted to understand the behavior of students with opposite LTs in the treatment group, to identify potential differences, and examine their attitudes towards gamification. For this, the following hypotheses are defined:

- H3: There is a behavioral difference between students (who have opposite LTs) in the treatment group.

- H4: There are differences between students with opposite LTs.

Fig. 15 shows a comparative analysis of students' engagement within each dimension, where analysis is performed on the characteristic data for the current dimensions (e.g. data regarding time and activities for the processing dimension). Further, Fig. 16 presents gamification-interaction related data.

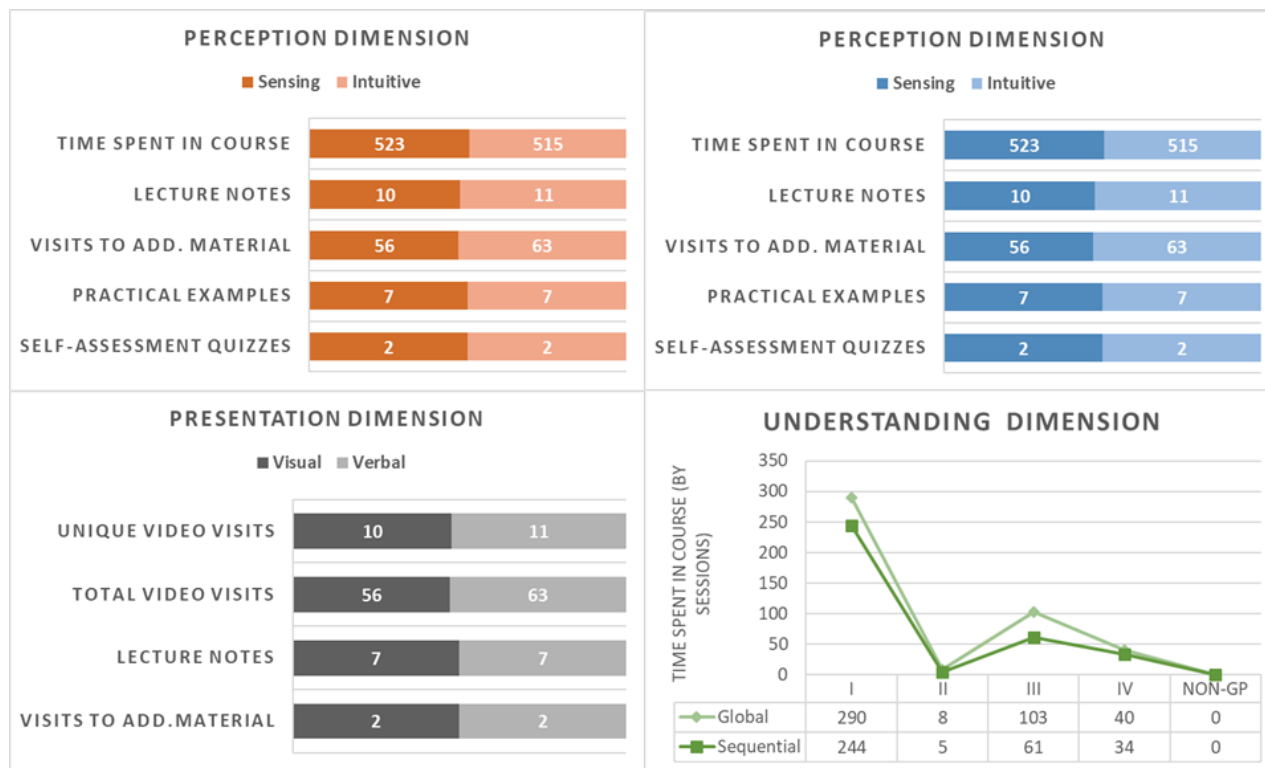

Figure 15. Median values of engagement data of students in the treatment group

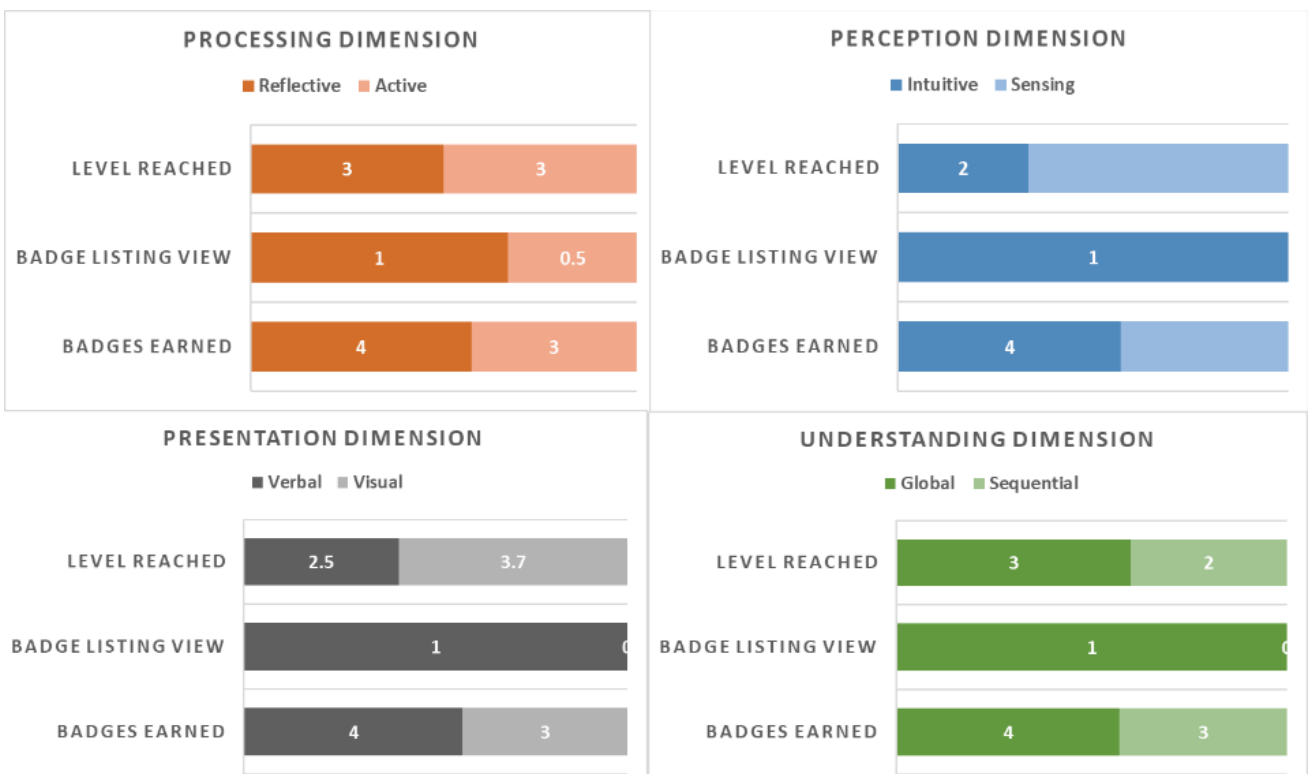

Figure 16. Median values of GE-related data of students from the treatment group 
Concerning the $\mathrm{H} 3$, the Man Whitney $\mathrm{U}$ test showed median number of submitted selfassessment quizzes score of reflective students was significantly higher (2.0) comparing to active (1.0), $\mathrm{U}=292.00, \mathrm{z}=-2.175, \mathrm{p}=0.03$. Further, a Kruskal-Wallis test was conducted to determine if there were differences in behavioral data scores between students that differed in their level of processing dimension: the "strong reflective" $(\mathrm{n}=2)$, "moderate reflective" $(\mathrm{n}=8)$, "mild reflective" $(\mathrm{n}=15)$, "strong active" $(\mathrm{n}=2)$, "moderate active" $(\mathrm{n}=15)$ and "mild active" ( $n=17)$ (see Fig. 17). It showed that number of earned badges score was significantly different between the different levels of processing dimension, $\chi 2(5)=14.028, p=.015$. The post hoc analysis revealed significant differences between the moderate active (mean rank $=3.00)$ and mild reflective (mean rank $=5.00)(\mathrm{p}=.047)$ students, but not between any other.

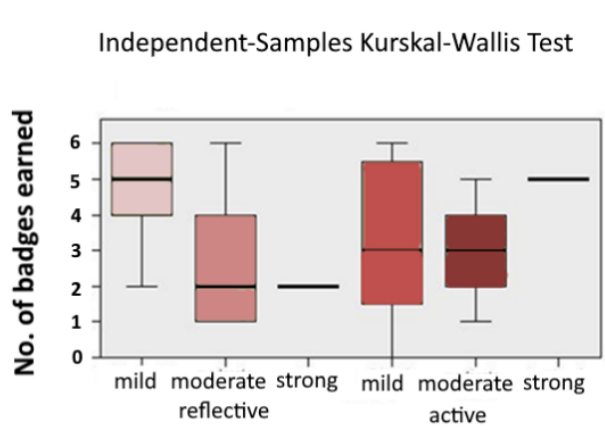

PROCESSING DIMENSION

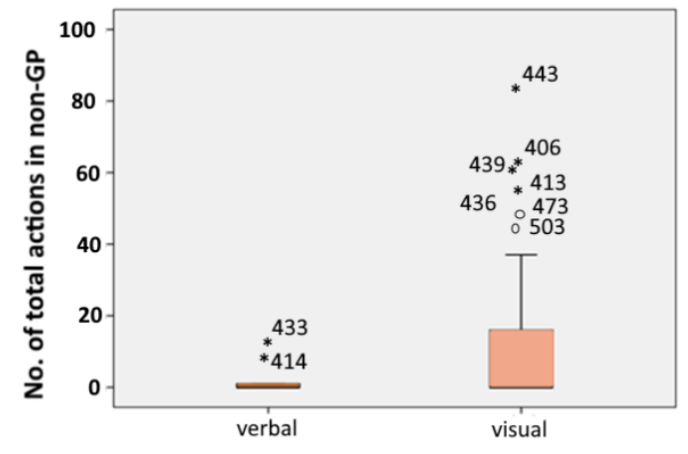

INPUT DIMENSION

Figure 17. Differences in engagement scores between student in processing and input dimension (treatment group)

The independent t-test showed students with visual LTs had statistically higher $\mathrm{t}(57)=-$ $1.476, p=.005$ number of submitted coding challenges mean score $M=1.04, S D=1.77$, comparing to the verbal students $\mathrm{M}=0.2, \mathrm{SD}=0.42$. Further, significant difference $\mathrm{t}(57)=-$ 1.236, $\mathrm{p}=0.035$ was observed for the mean score of number of total actions in non-GP between visual $\mathrm{M}=13.9, \mathrm{SD}=24.08$ and verbal students $\mathrm{M}=4.3, \mathrm{SD}=8.82$. From the above we conclude that the $\mathrm{H} 3$ is partially accepted.

\subsubsection{Students' perception of gamification}

At the end of the course, participants in the gamified group were asked to complete an evaluation survey. The survey was voluntary and 38/59 (64.4\%) students participated. By rating the statements on the 5-point Likert scale (being 1 equivalent to 'Strongly Disagree' and 5 to 'Strongly Agree') students expressed their opinions about each GE and the gamified environment in general (see Table 9). The reliability of scales was tested through Cronbach's $\alpha(0.919,0.878,0.852$ respectively), and its internal consistency is considered good since it is between 0.8 and 0.9. To investigate potential differences in opinion of students with different LTs we conducted a one-way ANOVA test, however, the test did not show any significant difference in students' scorings for the three gamification scale, hence $H 4$ is rejected.

Survey showed, students had moderately positive attitudes towards gamification (mean score between three and four) and would like to see GEs in other courses. However, results showed that they are not sure if gamification contributed to their engagement and productivity. Regarding the PBL system, results showed that leaderboards and levels were more attractive to students than badges and that the competitive nature of leaderboard motivated students to invest more effort in learning. To better understand the numerical measures of students' opinions, the survey also provided open questions regarding improvements that can be made in the system to support students' preferred behavior. Accordingly, three questions were asked 1) "In your opinion, what could be changed in the course to better support your learning?" 2) "Is there anything you would like to change 
about the Badge's system?" and 3) "Is there anything you would like to change about levels and XPs?".

Table 9. Evaluation survey items and the overall mean scores

\begin{tabular}{|l|l|c|c|}
\hline Scale & Example items in the scale & Mean & SD \\
\hline $\begin{array}{l}\text { General } \\
\text { opinion on } \\
\text { gamification }\end{array}$ & GEs made me more productive and engaged with the course. & 2.95 & 1.37 \\
\cline { 2 - 4 } & I have spent more time in the course because of the GEs. & 3.50 & 1.18 \\
\cline { 2 - 4 } & I would like to have GEs in other courses as well. & 3.42 & 1.20 \\
\hline $\begin{array}{l}\text { Opinion on } \\
\text { badges }\end{array}$ & During the course I have paid attention to badges. & 3.37 & 1.44 \\
\cline { 2 - 4 } & $\begin{array}{l}\text { By earning a badge, I felt that I achieved some progress in the } \\
\text { course. }\end{array}$ & 3.32 & 1.34 \\
\cline { 2 - 4 } & $\begin{array}{l}\text { I would like to have a page where I can see all the badges that } \\
\text { my colleges have earned. }\end{array}$ & 3.34 & 1.28 \\
\hline $\begin{array}{l}\text { Opinion on } \\
\text { levels, } \\
\text { leaderboards } \\
\text { and XPs }\end{array}$ & $\begin{array}{l}\text { I was motivated to earn more XPs when I saw that there are } \\
\text { students at a higher level. }\end{array}$ & 3.74 & 1.35 \\
\cline { 2 - 4 } & $\begin{array}{l}\text { Sometimes, I navigated through course just to earn some XPs } \\
\text { and to reach a new level. }\end{array}$ & 3.82 & 1.25 \\
\cline { 2 - 4 } & $\begin{array}{l}\text { I was motivated to progress more when I saw that I need to reach } \\
\text { a specified level to open a certain content. }\end{array}$ & 3.45 & 1.29 \\
\hline
\end{tabular}

Regarding the first question, the main complaints were about the video and sound quality of recorded lectures, and on the content of the slides that were "poor" or "too general". Further, a significant number of comments were related to the feedback system. Namely, to prevent cheating, we hide the correct answers on the e-assessment test until the deadline passes. It seems that the students (especially reflective and global) did not welcome this, as they wanted to see their answers instantly. Lastly, students expressed their wish to have more practical examples and the possibility to practice coding directly within the platform - "I would like to have a code editor where I could run my code and get immediate feedback on errors, eventually earn XPs for this work".

Regarding the badges, most of the suggestions were on their awareness, description, and transparency. The students enjoyed badges and would like to "make students more aware of them by putting them on the front page of the course". Next, they argue on badges description saying, "badges' name was too exaggerated" and suggested, "change labels to reflect what unlocks them" (answers mainly given by students with reflective and visual preferences). Lastly, they suggested the creation of a badges leaderboard as they would like to "know the badges of other people", "making it more competitive by showing who you're up against". A few students also suggested collaborative sharing of badges "An option to help other students, who have problems with earning them" (suggestion given by active students). Lastly, (sequential and sensing students) gave a few negative comments like "remove the badges from the course", and "I did not like the badges".

The results were quite similar when it comes to levels and XPs. Namely, the students who proposed badges removal had mainly the same attitude towards levels and XPs, which speaks of their general negative attitude towards this kind of gamification techniques. Some students reported technical problems, where sometimes they did not receive any points even if they watched a video or downloaded material - "I would like to have XPs if they can work properly; otherwise, it is confusing and irritating". Besides, they suggested that points should be rewarded only for "learning activities such as doing a quiz or watching a video, rather than any action taken in the course". Further, sensing students were strongly against the locked content, saying, "Level conditionality was discouraging". Lastly, almost every student said that rules on how to achieve a certain amount of points should have been specified and explained as well as the description of "what opportunities a new level brings". 
This paper described the primary research results of the application of PeGaM based on users' LTs. The results were analyzed through the PeGaM application in Moodle LMS that offered a course on JavaScript programming language. An exploratory experiment investigated gamification impact on students' engagement and the influence that LTs have on students' engagement in and attitudes toward gamified environments. The conducted experiments resulted in three major contributions.

First, by showing that gamification increased the number of watched videos and visits to additional material this study contributed to the existing literature on gamification success in regard to students' engagement and participation in online courses.

Second, the investigation revealed differences in students' engagement when students are grouped based on their LTs, and thus, supported the idea of considering users' traits in the gamification design process [8]. For example, students with reflective tendency submitted more self-assessment quizzes, had more actions in the course, visits to additional materials, and watched more videos compared to reflective students in a non-gamified group. Further, students with visual LT visited videos significantly more than their peers from the non-gamified group. Another positive influence of gamification is observed in the case of global students who accessed additional materials more often than students from the control group. Oppositely, observed is the negative influence of gamification on the number of actions to additional materials of sensing students. To summarize, the study showed the PBL system had a positive impact on reflective, visual, global, and intuitive students. The PBL system did not affect active, verbal, and sequential students, and had a somewhat negative effect on students with sensing LTs. These early study results partially confirmed $\mathrm{H} 1$ and $\mathrm{H} 2$, indicating that gamification influences one's engagement, but its influence is not the same for all students.

This is further confirmed with the investigation of students' engagement in the gamified group. Namely, statistical tests conducted to examine H3, showed students with opposite LTs behave differently (e.g., reflective students submitted more self-assessment quizzes compared to active students and earned statistically more badges). Based on the exposed, the preliminary evaluation results showed there is a relation between gamification and LTs, i.e. the impact of gamification on engagement varies depending on the students' LTs, and that LTs influence the student's behavior in the gamified environment.

Finally, the evaluation questionnaire showed that, in general, students had a positive attitude towards gamification, even though there were no significant differences when the attitudes of students with opposite LTs are compared (H4).

Although aware that the given indications are general, and do not provide specific guidelines for the design of personalized gamification, this research confirmed assumptions that the success of gamification is influenced by students' LTs. Hence, LTs should be further explored to discover the specific ways in which GE can be implemented to create a balanced gamified environment for all participants. Further, the study showed designing gamification is a complex process that needs to be iteratively revised in a step-by-step process proposed within PeGaM. As of, this study has made a step forward concerning the existing literature on LTs in gamification, because it has proposed, applied and evaluated a model for UC gamification design, and gave gamification designers and researchers in this field a framework to start with. In this manner, we summarize the key take-away messages derived from this study:

- Consider users' traits (LTs) in the gamification design, evaluation and analysis. Otherwise, if LTs are omitted, the gamification outcomes may be misleading (e.g. the comparisons of targeted outcomes between A and B group can show no differences between students, however, comparison between students with certain LTs from group A and group B can point to the important conclusions).

- PBL system has potential in the personalized gamification design and should not be omitted in future research (as authors of [5] proposed). 
- To eliminate uncertainty about which exact GE makes the difference and affects ones' engagement, participation, and experience, designers should incorporate only one GE per study group.

- Due to the lack of literature on how GEs and LTs mediate, when designing gamification based on users' LTs, designers should choose only one LTs as personalization criteria (e.g. game element " $\mathrm{X}$ " is used to boost engagement of students with sensing LT).

Implications on PBL design:

- Badges should be visually better positioned and reflect on students' knowledge and skills gained while doing the assignment. They should also be more competitive by showing who the student is up against.

- A student should be informed on which learning action brings how many XPs and what actions have to be taken to earn them. The system should also provide clear information on what a new level brings.

- Feedback system is needed, that will inform students about any change (i.e. students levelled up).

Regarding the validity of the results, we refer to the four threats to the validity of experimental studies: conclusion, internal, construct, and external validity threats [34]. The conclusion validity questions the statistical relationship between the treatment and the outcome. To avoid the possibility of inaccurate conclusions we used a satisfactory sample of students $(\mathrm{n}=124)$ and a low value for the significant measure $(\mathrm{p}=0.05)$. Next, the internal validity questions if the treatment is responsible for the outcome. Even though this study used a between-subject approach in which students are randomly assigned to the control and treatment groups, it is still possible to identify an internal validity threat regarding identifying which of the applied GEs influenced the outcome. Next, the construct validity questions how well a test or experiment measures up to its claims. In this study, construct validity is ensured due to the data triangulation on learners' engagement and attitudes. Finally, the external validity discusses the generalization of the study outcomes. This study provided a literature review on the effects that learners' characteristics have on gamification success. However, because this study is a pioneer in investigating personalized gamification based on LTs, and that it is using a learning dimension model that identifies LTs of engineering students specifically, it is not possible to state that the early outcomes of this study are generalizable. Besides, a limitation of this work is related to the extrinsic motivator (the three bonus points for the Web Technology module) that may affect their intrinsic motivation.

As already mentioned, this study presents the first-iteration and early evaluation of the PeGaM. Thus, in future work, we will create new interventions, to reduce the possibility of validity errors, and to clarify the remaining perplexities. Namely, to identify if and how, a certain GE influences behavior of a learner with a certain LT, we will create two gamified environments with the usage of two different GE, and address only one LTs. With this, we aim to explore and compare the impact of a single GEs on an individual learning dimension. Regarding the GEs to be selected for the follow-up study, we will adapt the PBL system based on the students' implications derived from the qualitative analysis.

Further, new GEs that may correspond to specific learning characteristics need to be identified and implemented, to test their effect in comparison to the PBL. For this, we will advise up to date literature on empirical personalized gamification study in regard to steps proposed in the 'Selection of game elements' stage of our model. In that way, we can observe how a specific GE works with a specific LT, isolated, and which GEs have more meaning for which learner, in the same setting. Further, we will extend the data triangulation by using an instrument such as the Student Engagement Questionnaire [33] to measure students' behavioral, cognitive, and emotional engagement. Additionally, interviews will be conducted to ensure a deeper knowledge of students' experience and attitudes in the course. Finally, to check potential external validity threats, the PeGaM 
framework should be generalized and applied to other contexts, by changing the personalization criteria (addressing different LTs, or using other LTs models).

\section{References}

[1] J. Lee, H.-D. Song, and A. J. Hong, "Exploring Factors, and Indicators for Measuring Students' Sustainable Engagement in e-Learning," Sustainability, vol. 11, no. 4, Art. no. 4, Jan. 2019, doi: 10.3390/su11040985.

[2] P. A. Willging and S. D. Johnson, "Factors that Influence Students' Decision to Drop out of Online Courses," Journal of Asynchronous Learning Networks, vol. 13, no. 3, pp. 115-127, Oct. 2009. doi:10.24059/olj.v13i3.1659.

[3] S. Deterding, M. Sicart, L. Nacke, K. O'Hara, and D. Dixon, "Gamification. using game-design elements in non-gaming contexts," in CHI '11 Extended Abstracts on Human Factors in Computing Systems, New York, NY, USA, May 2011, pp. 2425-2428, doi: 10.1145/1979742.1979575.

[4] "What is User Centered Design?," The Interaction Design Foundation. https://www.interactiondesign.org/literature/topics/user-centered-design (accessed Nov. 12, 2020).

[5] D. Dicheva and C. Dichev, "Gamification in Education: Where Are We in 2015?," Oct. 2015, pp. 1445-1454, Accessed: Sep. 19, 2018. [Online]. Available: https://www.learntechlib.org/primary/p/152186/.

[6] J. W. Keefe, "Assessment of Learning Style Variables: The NASSP Task Force Model," Theory Into Practice, vol. 24, no. 2, pp. 138-144, 1985.

[7] J. McDonald and T. Mayes, "The Changing Role of an Instructional Designer in the Implementation of Blended Learning at an Australian University," 2007, doi: 10.4018/978-1-59904-322-7.CH009.

[8] M. Böckle, I. Micheel, M. Bick, and J. Novak, "A Design Framework for Adaptive Gamification Applications," 2018, doi: 10.24251/HICSS.2018.151.

[9] J. Baldeón, I. Rodríguez, and A. Puig, "LEGA: A LEarner-centered GAmification Design Framework," 2016, doi: 10.1145/2998626.2998673.

[10] P. Buckley and E. Doyle, "Individualising gamification: An investigation of the impact of learning styles and personality traits on the efficacy of gamification using a prediction market," Comput. Educ., 2017, doi: 10.1016/j.compedu.2016.11.009.

[11] Schunk, D. H. "Learning theories: An educational perspective" (3rd. ed.), Upper Saddle River, NJ: Merrill/Prentice Hall, 2020.

[12] Myers, I. B., and Myers, P. B. "Gifts differing: understanding personality type". Palo Alto, Calif.: Davies-Black Pub. 1995.

[13] S. Cassidy, "Learning Styles: An overview of theories, models, and measures," 2004, doi: $10.1080 / 0144341042000228834$

[14] Felder, M., and Brent, R.: "Teaching and Learning STEM: A Practical Guide". 2nd edn. Josses Bass. 2016.

[15] P. A. Kirschner, "Stop propagating the learning styles myth", Computers \& Education, Vol 106, pp. 166-171, 2017, doi:10.1016/j.compedu.2016.12.006.

[16] R. Felder, and J. Spurlin, "Applications, reliability and validity of the Index of Learning Styles", International Journal of Continuing Engineering Education and Life-Long Learning 21(1): vol21, No. 1 , pp. 103-112, 2005.

[17] R. N. Landers, "Developing a Theory of Gamified Learning: Linking Serious Games and Gamification of Learning," Simulation \& Gaming, vol. 45, no. 6, pp. 752-768, Dec. 2014, doi: $10.1177 / 1046878114563660$

[18] S. Nicholson, "A RECIPE for Meaningful Gamification," in Gamification in Education and Business, T. Reiners and L. C. Wood, Eds. Cham: Springer International Publishing, pp. 1-20, 2015, doi: 10.1007/978-3-319-10208-5_1.

[19] J. Hamari, J. Koivisto and H. Sarsa, "Does Gamification Work? -- A Literature Review of Empirical Studies on Gamification," 2014 47th Hawaii International Conference on System Sciences, Waikoloa, HI pp. 3025-3034, 2014, doi:10.1109/HICSS.2014.377.

[20] "Moodle plugins directory: Set: Gamification." https://moodle.org/plugins/browse.php?list=set\&id=88 (accessed Nov. 12, 2020).

[21] A. M. Toda et al., "A Taxonomy of Game Elements for Gamification in Educational Contexts: Proposal and Evaluation," in 2019 IEEE 19th International Conference on Advanced Learning Technologies (ICALT), Jul. 2019, vol. 2161-377X, pp. 84-88, doi: 10.1109/ICALT.2019.00028.

[22] A. Antonaci, R. Klemke, C.M. Stracke, and M. Specht, "Identifying Game Elements Suitable for MOOCs.” In: Lavoué É., Drachsler H., Verbert K., Broisin J., Pérez-Sanagustín M. (eds) Data Driven Approaches in Digital Education. EC-TEL 2017. Lecture Notes in Computer Science, vol 10474. Springer, Cham, 2017. doi:10.1007/978-3-319-66610-5_26.

[23] J. W. Creswell, Research Design: Qualitative, Quantitative, and Mixed Methods Approaches. SAGE Publications, 2014. 
Zaric., et al., A Fundamental Study for Gamification Design: Exploring Learning Tendencies' Effects pag. 25

[24] "Moodle plugins directory: Level up! - Gamification ๖ ." https://moodle.org/plugins/block_xp (accessed Nov. 12, 2020)

[25] F. J. Gravetter and L. A. B. Forzano, Research Methods for the Behavioral Sciences. Cengage Learning, 2011.

[26] T. Frommen, "Development of Learning Style Questionnarie and Visualization Plugin for the Moodle LMS", Master thesis, RWTH Aachen University, Germany, 2018. doi: 10.18154/RWTH-2018-229307

[27] NC State University Homepage, https://www.webtools.ncsu.edu/learningstyles/, last accessed 2019/10/10.

[28] G. D. Kuh, "What we're learning about student engagement from NSSE: Benchmarks for effective educational practices". Change: The Magazine of Higher Learning, 35(2), pp. 24-32, 2003. doi:10.1080/00091380309604090.

[29] N. Zaric, S. Judel, R. Roepke, U. Schroeder, ILSA- an integrated learning styles analytics system, In proceedings of the The international conference on education and new learning technologies At: Palma de Mallorca (Spain). 1st - 3rd of July, 2019, doi: 10.21125/edulearn.2019.0770

[30] A. Field, Discovering statistics using SPSS (4th ed.). London: SAGE Publications Ltd, 2020

[31] D. J. Sheskin, Handbook of Parametric and Nonparametric Statistical Procedures, 4th ed. Chapman \& Hall/CRC, 2007.

[32] S. Axelrod, A Review of: "Gladwell, M. (2008). Outliers: The Story of Success.", Child \& Family Behavior Therapy, 31:4, pp. 320-323, 2009 doi:10.1080/07317100903333210.

[33] H. Coates, "Student engagement in campus-based and online education: University connections". University connections (Vol. 9780203969). London: Routledge, 2006, doi: 10.4324/9780203969465.

[34] C. Wohlin, P. Runeson, M. Höst, M.C. Ohlsson, B. Regnell, and A. Wesslén, "Experimentation in Software Engineering". Springer Science \& Business Media, New York, 2012. doi: 10.1007/978-3642-29044-2. 